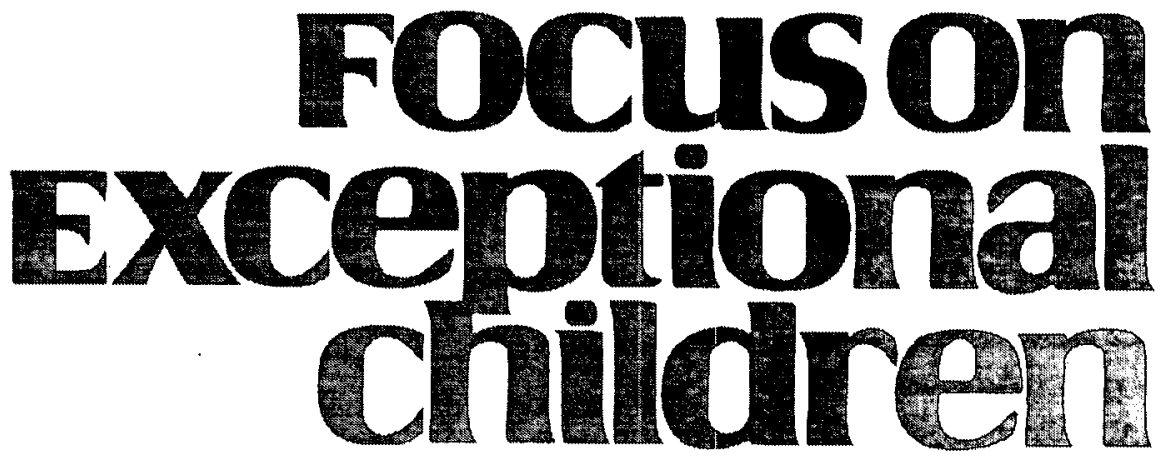

\title{
RTI School-Based Practices and Evidence-Based Models
}

\author{
Daryl F. Mellard, Amelia Stern, and Kari Woods
}

\begin{abstract}
Response to intervention (RTI) is widely used as a framework for providing high quality instruction and interventions that are matched to students' needs, as well as a means of integrating important federal policies. "A multi-tiered system of interventions is recommended as a means to integrate educational problem-solving across educational levels, consistent with federal legislation (e.g., Individuals with Disabilities Education Improvement Act of 2004; No Child Left Behind Act of 2001,) and scientific research" (Batsche, 2006, p. 3), including both general and special education. The concept of RTI did not begin with these broad goals; rather, RTI was initially conceived as a prevention framework providing early intervention to students at risk of reading failure. Special educators and others soon began to see that RTI frameworks could contribute important information to the identification of specific learning disabilities (SLD). This recognition was eventually encoded in IDEA 2004 (P.L. 108-446), permitting RTI as a component of SLD identification. The RTI idea continued to grow, with application made to not just reading but all academic content areas, as well as behavior. Further, RTI processes extended beyond early identification to annual efforts to identify students at risk of academic or behavioral failure throughout elementary, middle, and high school (Johnson, Smith, \& Harris, 2009).

Initially, variability in the way that RTI was conceptualized, researched, and practiced was expected, and even necessary, as new ideas transformed into current state and local educational agencies policies and practices. However, when IDEA 2004 permitted alternative assessments of SLD identification, such as including students' responsiveness in an RTI framework, this variability began to pose equity, quality, and efficiency issues for state education agencies, school districts, and local schools (Griffith, Parsons, Burns, VanDerHeyden, \& Tilly, 2007). A review of nine state education agencies' RTI documents (Bocala, Mello, Reedy \& Lacireno-Paquet, 2009) found a high degree of consistency with a model prescribed by National Research Center on Learning Disabilities (NRCLD; Mellard, Byrd, Johnson, Tollefson, \& Boesche, 2004), yet within this framework states allowed for substantial local discretion. Such place-to-place differences in local RTI implementation have implications for equitable distribution of resources, SLD identification, disproportional representation of some groups, and the proper role of special educators (Council for Exceptional Children [CEC], 2008; Fletcher \& Vaughn, 2009; Fuchs \&
\end{abstract}

Dr. Mellard is an associate research professor, Ms. Stern is a graduate research assistant, and Ms. Woods is a program assistant at the University of Kansas, Center for Research on Learning. 
Deshler, 2007; Fuchs, Fuchs, \& Compton, 2004; Hollenbeck, 2007; Mellard \& Johnson, 2008, 2010; Reynolds \& Shaywitz, 2009). Studies demonstrated how such local decision making resulted in wide variability from district to district in tier structures, screening and progress measures, cut . scores and other decision criteria, and the potential for equity issues that challenge the viability of RTI (Mellard, McKnight, \& Jordan, 2010; Mellard, McKnight \& Woods, 2009). Likewise, the CEC and Learning Disabilities Association (LDA, 2006) expressed concerns about RTI potentially causing delays in comprehensive evaluation referrals for children suspected of having SLD and emphasized the need for partnership of all school personnel and families to identify and address the academic and behavioral needs of learners.

In light of these issues, Fuchs and Fuchs (2009) argued for a unified model of RTI that "encourages shared understanding among all school-based practitioners about intervention intensity, roles and responsibilities, and constructive

\section{Focuson
Exceptional children}

ISSN 0015-511X FOCUS ON EXCEPTIONAL CHILDREN (USPS 203-360) is published monthly except June, July, and August as a service to teachers, special educators, curriculum specialists, administrators, and those concerned with the special education of exceptional children. This publication is annotated and indexed by the ERIC Clearinghouse on Handicapped and Gifted Children for publication in the monthly Current Index to Journals in Education (CIJE) and the quarterly index, Exceptional Children Education Resources (ECER). The full text of Focus on Exceptional Children is also available in the electronic versions of the Education Index. It is also available in microfilm from Serials Acquisitions, National Archive Publishing Company, P.O. Box 998, Ann Arbor, MI 48106-0998. Subscription rates: individual, $\$ 50$ per year; institutions, $\$ 68$ per year. Copyright $\bigcirc 2011$, Love Publishing Company. All rights reserved. Reproduction in whole or part without written permission is prohibited. Printed in the United States of America. Periodical postage is paid at Denver, Colorado. POSTMASTER: Send address changes to:

Love Publishing Company

Executive and Editorial Office P.O. Box 22353

Denver, Colorado 80222

Telephone (303) 221-7333

\section{CONSULTING EDITORS} Steve Graham
Vanderbilt University

$$
\begin{aligned}
& \text { Ron Nelson } \\
& \text { University of Nebraska-Lincoln }
\end{aligned}
$$

Eva Hom

University of Kansas
Carrie E. Watterson Senior Editor
Stanley F. Love Publisher and effective relationships between general and special education" (p. 41). Fletcher and Vaughn, however, indicated that they were "less interested in promoting a unitary model ... as long as schools use ongoing student data to inform decisions" (2009, p. 48).

Even as these debates continue, schools continue to implement a variety of RTI frameworks. Thus, our purpose here is to demonstrate the variability in school-based practices and to describe some prominent, evidence-based RTI models. We discuss the implications of these differences in practices and evidence-based models for learners, educators, and administrators. We anticipate that our descriptions and discussion will assist education leaders in making informed decisions when planning, selecting, and implementing an RTI model that best fits their context.

\section{VARIABILITY IN SCHOOL-BASED RTI PRACTICES}

From a survey of and interviews with schools practicing RTI, we briefly describe five elementary school-based RTI frameworks with the same overall purpose-to improve school-wide reading achievement (Mellard, McKnight, Woods, \& Frey, n.d.). None of these schools reported fully adopting an evidence-based model and did not consider their model fully implemented at the time. Rather, each school implemented the RTI components that best fit its particular context, value system, and available resources. In all cases, the school used RTI as a component of their comprehensive evaluation for SLD identification.

School A. School A's 517 students were in grades K-4. The school's RTI model had four tiers in which all except 5 students with severe cognitive disabilities were screened for reading risk and placed in appropriate instruction. Seventysix percent of students received instruction in Tier 1, where Signatures reading series (Harcourt Brace) was supplemented by repeated readings, sight word reading, paired reading, and Blast Off readers (Bellwether Media). Screening and progress monitoring was based on Dynamic Indicators of Basic Early Literacy Skills (DIBELS; Good \& Kaminski, 2002) oral reading fluency (ORF) benchmarks for first and second grades, DIBELS ORF benchmarks and percentile ranking (below 56th) on Terra Nova (CTB McGraw-Hill) for third grade, and Hasbrouck and Tindal (1992) 50th and 25th percentile rankings in ORF for fourth grade.

School B. School B enrolled 366 students in grades K-5. Its RTI model had three tiers in which all except a few students with low cognitive skills were screened. On average, $80 \%$ of students received Tier 1 instruction with the following programs and materials: Literacy Place (Scholastic), Read Well $K^{\circledR}$ and Read Well $I^{\circledR}$ (Sopris West Educational 
Services), Guided Reading, Corrective Reading and Corrective Decoding (McGraw-Hill SRA), Reading Mastery (McGraw-Hill SRA), REWARDS ${ }^{\circledR}$ (Cambium Learning Group), Peer-Assisted Learning Strategies ${ }^{\circ}$ (Vanderbilt Kennedy Center), and Read Naturally (Read Naturally, Inc.). Screening for risk and response to instruction in the core curriculum was determined based on the dual discrepancy data of level and slope (rate of growth) using DIBELS measures at all grade levels and other evidence of responsiveness in reading components.

School C. School C had an enrollment of 977 students located in three facilities with a four-tier RTI model. All students were screened with the exception of a few students with severe disabilities who could not complete the assessment process. Sixty-three percent of students participated solely in Tier 1 core instruction using Houghton Mifflin. Reading (Houghton Mifflin) and The Language Tool Kit (Orton Gillingham), and an additional $23 \%$ in Reading Plus. ${ }^{(1)}$ (Taylor Associates/Communications, Inc.). Screening and response to instruction in the core curriculum was based on level and slope using DIBELS benchmarks and below 70 th percentile on local benchmark assessments in $\mathrm{K}-1$; for grades 2-5, CBM fluency levels, Houghton-Mifflin, and Gates-McGinitie reading norms.

School D. School D's enrollment of 380 students was in grades K-5. This school's RTI model had three tiers in which all students participated except those students whose parents or IEP team opted for exclusion from the screening process. Core instruction in Tier I was provided to $68 \%$ of students using Direct Instruction (MacMillian-McGraw), Read Naturally (Read Naturally, Inc.), REWARDS ${ }^{\infty}$ (Cambium Learning Group), Open Court Phonemic Awareness and Phonics Kit (McGraw-Hill), and Waterford Early Reading Program ${ }^{\mathrm{rm}}$ (Pearson). Screening for risk and response to instruction in the core curriculum was determined by dual discrepancy scores below the 25 th percentile on level and the slope on one or more DIBELS indices. In addition, the school staff used confirmatory data from CBMs, the Stanford Achievement Test (Pearson), Qualitative Reading Inventory (Pearson), and Ekwall Reading Inventory (Allyn \& Bacon) in their decisions.

School E. School E had a total enroliment of 480 students in grades $\mathrm{K}-5$, with $257 \mathrm{~K}-3$ students included in RTI data. At the time of these activities, the school reported only two liers of intervention, with $47 \%$ of students in Tier $1,19 \%$ in Tier 2, and the remaining students receiving instruction through English language learner and special education programs. Special education was a separate instructional setling. Core instruction used Open Court (McGraw-Hill) curriculum. Students' risk status was based on a dual discrepancy criterion indicated by the level and slope of DIBELS benchmarks.

\section{EQUITY AND EFFICIENCY IMPLICATIONS}

While we can describe what these five schools implemented, we cannot test whether students would receive the same level of instructional intensity from one school to the next (i.e., equitable treatment). Nor can we evaluate whether schools are providing services in the most efficient manner (i.e., not overidentifying need for intensive instruction). However, in our view, Schools D and E are not "exemplary" implementations because they delivered intensive interventions to a high percentage of students. A well-developed RTI model is intended to prevent academic and behavioral difficulties and the need for extensive intervention.

Without a prevention focus, an RTI system cannot function efficiently. Schools D and E's distributions of students among the tiers and services suggest that instruction and the core curriculum were deficient for a significant number of students. These data provide programmatic evidence that, for far too many students, the core curriculum did not provide a positive instructional experience and therefore directed too many resources toward intensive services for these students. An inefficient model is not likely to have a robust or strong implementation or even be sustainable over time. Nor would we expect that such a model would generate student outcome evidence (e.g., marked improvements and positive trends from historical data) that would support continuation of the system.

\section{COMPARISON OF EVIDENCE-BASED RTI MODELS}

The various ways in which schools have implemented RTI are, in part, the result of having limited guidance from theory and research at the time they adopted their practices. However, several evidence-based RTI models have been validated in the literature, and school staff could now adopt them. We chose seven such models to describe and compare. We identified them by conducting a literature review using such search terms as RTI, Response to Intervention, and Responsiveness to Intervention. We excluded publications for which a complete framework of RTI (i.e., screening, progress monitoring, and tiered interventions) was not published. Many research articles have been written about a specific component of RTI, but our additional searches for information on the other vital components of RTl from those authors was inconclusive. The selected models were supported by varying numbers and quality of empirical studies and were nol typically available in a complete or integrated package for school staffs. At this time, research does not provide a preponderance of evidence to support one RTI model over another, and this review should not be treated as comprehensive but rather as a starting point for planning 
and evaluating available resources prior to implementation.

Proponents or designers of the seven selected models are: Batsche, Curtis, Dorman, Castillo, and Porter (2008); Fuchs and Fuchs (2005); Johnson, Mellard, Fuchs, and McKnight (2006); Vaughn (2005); Shinn (2008); Chun and Witt (2008); and Sugai and Horner (2007a). We emphasize at the outset of our comparisons that these models have more points of commonality than of difference. However, the distinctions among models have varying levels of importance, depending on one's values on specific topics (e.g., ease of implementation, academic or behavioral emphasis, school structures, research foundation, match to a school or district's professional development, and resource supports).

\section{Overviews}

Batsche et al. (2008) emphasized two unique features: exclusive use of a problem-solving approach and application to both behavioral and academic outcomes. Like many other models, this model is primarily designed for elementary schools and values early intervention, effective instruction, and multi-tier service delivery in the context of problem-solving processes.

In contrast to the problem-solving approach, Fuchs and Fuchs (2005), Johnson et al. (2006), and Vaughn (2005) recommended standard treatment protocols, that is, substantially uniform and well-established conventions governing the instructional treatment of all students. These models differ slightly from one another, in that Fuchs and Fuchs addressed reading and math, while the other two include only reading; further, Vaughn extended beyond the elementary level to eighth grade. Vaughn cautioned that her approach is descriptive rather than prescriptive and thus values flexibility to incorporate a variety of research-based programs where appropriate. Like other models, Vaughn included validated interventions selected according to students' needs, delivered individually or in a variety of group sizes and in a setting makes that the most sense for a given school.

Fuchs and Fuchs (2005) placed emphasis on early identification through assessment of students at risk of academic failure. Johnson et al. (2006) built specifically on this principle by designating essential components to accomplish the same goal Fuchs and Fuchs articulated. The components of Johnson et al. reflected IDEA and NCLB statues by requiring: (a) scientifically-based instruction for all students, (b) school-wide screening for students at risk of academic failure, (c) research-based interventions appropriate to student needs, (d) continuous progress monitoring with the interventions, and (e) fidelity to the process as prescribed.

Shinn's (2008), Chun and Witt's (2008), and Sugai and Horner's (2007a) models combine standard treatment protocol with problem-solving methods. Shinn applied the approach to secondary academics (middle school and high school), while Chun and Witt applied it to academics at any grade level, and Sugai and Horner used the combined method to address behavior at any grade level. Chun and Witt valued empiricism, efficiency, and simplicity of interventions and procedures. Schools using this model accomplish these goals, in part, by defining problems in solvable terms, using very targeted interventions. Shinn emphasized scientifically-based progress monitoring tools and two issues particularly relevant in secondary settings: basic skill interventions for content learning and consultation with the classroom instructors. Shinn suggested combining his academic model with Sugai and Horner's behavioral model, when needed. Sugai and Horner designed their model to achieve functional behavioral outcomes and prevent or reduce prevalence of behavioral incidents. They placed value on balance among data, practices, fidelity, and outcomes and emphasized redesigning instruction and environment to improve behavior. Table 1 presents an overview of each model by the type of interventions the model employs, the applied content areas, grade levels for appropriate use, and its core principles.

\section{Tier Structure}

Each model has a three-tiered intervention structure. Table 2 describes the models' three primary tiers and intervention features at each tier. Consensus exists around the definition of the first tier, Tier 1 , as effective classroom instruction with a viable general education curriculum. Consistent with an emphasis on efficiency, Chun and Wilt (2008) allowed Tier 1 to include reasonable modifications to curriculum or instruction, which could possibly avoid more intense, costly, or disruptive Tier 2 intervention. Shinn (2008) included behavioral interventions and supports during academic instruction, recognizing the importance of classroom participation in middle and high school content courses.

Tier 2 in each model represents a context for providing interventions to students who do not respond to general instruction or who were predicted to be at risk through a screening process. Tier 2 is regarded as more intense instruction, though not necessarily a different curriculum. Models that emphasize a standard treatment protocol are more likely to implement a curricular change. Each model describes Tier 3 as more intensive instruction than in Tier 2, and the Fuchs and Fuchs (2005), Johnson el al. (2006), and Shinn (2008) models explicitly identified Tier 3 as special education or highly individualized instruction.

\section{Screening}

Most RTI models operate from the principle that the purpose of screening is to identify those students who may be 
TABLE 1. Model Overviews

\begin{tabular}{|c|c|c|c|c|c|}
\hline Principle Author & Model Name & Type & $\begin{array}{l}\text { Content } \\
\text { Area(s) }\end{array}$ & $\begin{array}{l}\text { Targeted } \\
\text { Grades }\end{array}$ & Core Principles \\
\hline Batsche et al. & $\begin{array}{l}\text { Problem Solving } \\
\text { Model / RTI } \\
\text { (PSM/RTI) }\end{array}$ & $\begin{array}{l}\text { Problem } \\
\text { solving }\end{array}$ & $\begin{array}{l}\text { Behavior } \\
\text { Academics }\end{array}$ & Elementary & $\begin{array}{l}\text { Teach all children effectively } \\
\text { Early intervention } \\
\text { Multi-tier service delivery model } \\
\text { Problem-solving methodology that } \\
\text { defines and validates the problem, } \\
\text { identifies and implements interven- } \\
\text { tion, and evaluates student response } \\
\text { to intervention }\end{array}$ \\
\hline Fuchs \& Fuchs & RTI & $\begin{array}{l}\text { Standard } \\
\text { treatment } \\
\text { protocol }\end{array}$ & $\begin{array}{l}\text { Reading } \\
\text { Math }\end{array}$ & Elementary & $\begin{array}{l}\text { Assessment and identification linked to } \\
\text { early intervention }\end{array}$ \\
\hline Johnson et al. & RTI & $\begin{array}{l}\text { Standard } \\
\text { treatment } \\
\text { protocol }\end{array}$ & Reading & Elementary & $\begin{array}{l}\text { Scientifically-based instruction } \\
\text { School-wide screening } \\
\text { Continuous progress monitoring } \\
\text { Research-based interventions } \\
\text { Fidelity of implementation }\end{array}$ \\
\hline Vaughn & RTI & $\begin{array}{l}\text { Standard } \\
\text { treatment } \\
\text { protocol }\end{array}$ & Reading & $K-8$ & $\begin{array}{l}\text { Descriptive, not prescriptive model } \\
\text { Flexible to incorporate any research- } \\
\text { based program } \\
\text { Interventions based on student needs } \\
\text { Interventions delivered in whole class, } \\
\text { small group, pairs, } 1: 1 \\
\text { Instructional groups can be within } \\
\text { class, within grade, or across grade }\end{array}$ \\
\hline Shinn & $\mathrm{RT}$ & Combined & Academics & Secondary & $\begin{array}{l}\text { Scientifically-based progress } \\
\text { monitoring tools } \\
\text { Basic skill interventions for content } \\
\text { learning } \\
\text { Positive Behavior Intervention \& } \\
\text { Support (PBIS) } \\
\text { Mainstream consultation }\end{array}$ \\
\hline Chun \& Witt & $\begin{array}{l}\text { System to } \\
\text { Enhance } \\
\text { Educational } \\
\text { Performance } \\
\text { (STEEP) }\end{array}$ & Combined & Academics & All Levels & $\begin{array}{l}\text { Empirical, efficient, and simple } \\
\text { interventions and procedures } \\
\text { Define student problems in solvable } \\
\text { terms } \\
\text { Target interventions on academic skills }\end{array}$ \\
\hline Sugai \& Horner & $\begin{array}{l}\text { Positive } \\
\text { Behavior } \\
\text { Intervention \& } \\
\text { Support (PBIS) }\end{array}$ & Combined & Behavior & All Levels & $\begin{array}{l}\text { Balancing data, practices, fidelity, and } \\
\text { outcomes } \\
\text { Functional behavioral outcomes } \\
\text { Preventing behavioral incidents and } \\
\text { reducing prevalence } \\
\text { Redesign teaching/environment to } \\
\text { improve behavior }\end{array}$ \\
\hline
\end{tabular}

at risk or struggling to achieve academic or behavioral outcomes. Table 3 presents screening and progress monitoring methods. Batsche et al. (2008) used screening data to eliminate two potential problems before designating students as at risk of school failure. First, they suggested that if universal screening yields less than an $80 \%$ pass rate, the general education or core curriculum may not be effective and thus reflects a systemic problem to be resolved. In the previously 
TABLE 2. Intervention Features by Tier

\begin{tabular}{ll}
\hline Principle Author & $\begin{array}{c}\text { Tier 1 } \\
\text { Primary Prevention }\end{array}$ \\
\hline Batsche et al. & $\begin{array}{l}\text { Core instruction for all students } \\
\text { school may make modifica- } \\
\text { tions to general instruction to } \\
\text { increase effectiveness and/or } \\
\text { to reduce disproportionality }\end{array}$ \\
Fuchs \& Fuchs & $\begin{array}{l}\text { Classroom instruction that pro- } \\
\text { vides at-risk students evi- } \\
\text { denced-based curriculum with } \\
\text { a sound instructional design }\end{array}$
\end{tabular}

Johnson et al. Effective, scientifically-based instruction in general education

Vaughn

Shinn

Chun \& Witt

Sugai \& Horner
Classroom instruction or core reading program for all students
High quality, research-based instruction in content knowledge with behavior interventions and supports, school-wide pedagogy with teaching routines and strategies, effective classroom management, study and organizational skills, curriculum modification, and an objective, open grading system

Core curriculum with problem solving for individual student modifications

Stated behavioral expectations, teaching expectations and strengthening expected behaviors, and consequences for behaviors for all students and staff in every settings and with a data collection system
Tier 2

Secondary Prevention

Supplemental instruction, in addition to core, for smallgroup instruction at intensity and frequency necessary to ensure improvement

Supplementary, diagnostic instructional trials for nonresponders, provided in small groups of students with similar abilities for 30 minutes three times per week with a qualified teacher or aid; includes frequent progress monitoring

Specialized group instruction that supplements general education for at-risk students to remediate deficits; provided in small groups, 3 or 4 times per week, in 30 to 60 minute sessions for 9 to 12 weeks

Supplemental instruction, in addition to core instruction, for identified students; e.g., K-3 small group, 20-30 minutes daily, 10-20 weeks; middle school 50 minutes daily, 12 weeks

Remedial programs to help generalize learning to core curriculum targeted towards basic skills and content knowledge, such as remedial reading programs

Class-wide peer tutoring and peerassisted learning strategies for whole class, if needed, and standard protocol interventions selected from pool of interventions based on student needs

Specialized interventions for unresponsive students, including structure and predictability, positive reinforcements, and good home-school communication
Tier 3

Tertiary Prevention

Intensive instruction, in addition to core, for a very small group or individuals with narrow focus on defined skills instruction

Interventions that are generally systematic and explicit, with increased frequency and duration in homogenous group or 1:1 by highest expertise teacher with students eligible for special education

Special education or highly individualized instruction

Intensive instruction for struggling students based on needs, not necessarily special education but typically provided by a reading teacher, special educator, or trained interventionist

Intensive or special education matched to student needs and/or mainstream consultation and coaching to support students

Increased frequency and duration or change of intervention based on problem-solving methods

Function-based, personcentered, and intensive interventions for secondarily unresponsive students provided with consideration to school, family, community, and mental health context 


\section{TABLE 3. Screening and Progress Monitoring Features}

\section{Principle Author Screening Features \\ Batsche et al. \\ Screen all students at beginning of school year with an $80 \%$ pass rate indicating an effective core curriculum \\ Assess group identified as at risk for overrepresentation \\ Students below benchmark identified as at risk; enter into individual problem-solving process \\ For behavior, consider student, teacher, peer, curriculum, classroom/school, and family/community factors \\ Fuchs \& Fuchs $\quad$ Screen all students to identify at-risk status At-risk students monitored 5 to 8 weeks to reduce false positives and identify those not responding to instruction before placement in Tier 2 \\ Johnson et al. \\ School-wide screening to identify at-risk students, three times per year \\ Overidentification is a worse error than under- identification \\ Use screening and at least 5 weeks of weekly progress monitoring to identify students needing intervention}

Vaughn

Shinn

Chun \& Witt

Sugai \& Horner
Benchmark testing all K-3 students three times per year Screening in word identification, comprehension, and fluency

Skill testing middle school students

Universal reading screening with grades $5,6, \& 9$ using Maze CBM probes

At high school level, screening is individual and targeted rather than universal

Universal screening with validated CBMs

Administration of screening probes follows a scripted implementation protocol

Determine effectiveness of core instruction, disproportionality, differences among classes before examining individual student data placement in Tier 2

Screening data examined at school, class, and student levels
Performance motivation vs. skill assessment before

\section{Progress Monitoring Features}

CBMs and behavior measures at frequency sufficient to inform instruction and evaluate students' responsiveness to intervention

Chart progress vs. a baseline of peer performance (not standardized reference point)

At-risk students monitored 5 to 8 weeks using CBM probes before intervention

Tier 2 progress monitored weekly for 8 weeks during intervention

Progress monitor more frequently for nonresponders

Progress monitor at all tiers with screening probes used as progress monitoring of students in Tier 1

Progress monitor at-risk students for at least 5 weeks before moving to Tier 2

Progress monitor students in Tier 2 and Tier 3 at least 2 times per week.

Formative assessment for instructional changes

Frequency spectrum from three times per year for those making adequate progress to weekly for those with persistent reading deficits

Use standardized CBM tools and sufficient alternate forms of equal difficulty for repeated testing; course grades can be used with weekly rates of improvement toward specified goals in high school

Tiers 1 and 2 nonresponsiveness determined after 4 to 6 weeks of progress monitoring

Tier 3 progress monitoring more frequent depending on intervention

Oral reading fluency, weekly, use median of three probes

Reading comprehension using Maze CBM every 4-5 weeks

One math probe administered weekly

Collect and review data on individual students, classrooms, and school-wide on a weekly, monthly, quarterly, and annual basis.

Office discipline referrals, academic achievement scores, attendance/tardies, suspensions, and behavior incidents monitored on a weekly, monthly, and annual basis 
described examples, several schools' data reflected such systemic problems. Second, to eliminate any problem of disproportionality in placements, Batsche et al. called for evaluating the group identified as at risk for overrepresentation of a particular demographic characteristic (e.g., racial or ethnic status). If bias is indicated, individual student problemsolving processes should address it. Otherwise, the faculty would then begin a problem-solving process for each student judged to be at risk. In the case of behavior issues, the model is designed to collect multiple perspectives for the problem-solving process, including perspectives of the student, teacher, peers, curriculum, classroom, school, and family or community.

During screening, Fuchs and Fuchs (2005) emphasized avoiding false positive predictions of students at risk. They suggested leaving the identified subgroup in general classroom instruction for 5 to 8 weeks while monitoring their progress to confirm nonresponsiveness to instruction. This two-step confirmatory approach conserves resources for only those students clearly needing secondary or tertiary interventions because of their lack of progress in the core curriculum. Similarly, Johnson et al. (2006) suggested at least 5 weeks of monitoring for students at risk in Tier 1 before moving a student to Tier 2 . They also suggested screening all students three times per year to identify additional students who are not responding to the instruction throughout the year.

Like Johnson et al. (2006), Vaughn (2005) recommended reading assessments three times a year for all students in $\mathrm{K}-3$. This more frequent screening is important at these early grade levels because of the multiple stages of development experienced by beginning readers in a relatively short time period. Vaughn suggests screening for word identification, comprehension, and fluency skills. For middle school students, the model recommends skills testing.

Chun and Witt (2008) suggested standardized curriculumbased measures (CBM) for universal screening. Because of this model's emphasis on efficiency, they recommended that administration of screening probes follow a scripted implementation protocol. As with Batsche et al. (2008), Chun and Witt (2008) emphasized using screening results to determine the effectiveness of core curriculum, test disproportionality of minority groups in the at-risk category, and identify differences among classes before examining individual student data. This model introduces a second assessment with a performance reward to ascertain whether low-performing students simply lacked motivation during screening (a performance/skill or Can't Do/Won't Do assessment). Notice that this second assessment is administered only to those students who were judged as at risk on the initial screening.

At the secondary level, Shinn (2008) recommended screening with the selective use of CBM Maze reading tasks
(Fuchs \& Fuchs, 1992) with fifth-, sixth-, and ninth-grade students. At high school level, they recommended individualized, targeted screening rather than universal screening. Conversely, Sugai and Horner's (2007a) behavioral model prescribes widespread data collection and comparisons at school, class, and student levels to support balanced decision making.

\section{Progress Monitoring}

All models include progress monitoring to determine students' growth or improvement over time, which then informs instruction or intervention decisions. As a general rule, when the intensity of an intervention increases, the frequency of progress monitoring increases. However, the differences among models are in the details. Table 4 illustrates decision-making criteria for movement between tiers.

Batsche et al. (2008) offered a loose guideline and indicated that the frequency of progress measurement should be sufficient to inform instruction and evaluate responsiveness to intervention-leaving open the choice to fit the specifics of the problem-solving process. The three proponents of standard protocol models offer more specificity about the frequency of progress monitoring. Fuchs and Fuchs (2005), as previously discussed, suggested 5 weeks of preliminary progress monitoring in Tier 1 , weekly monitoring for 8 weeks in Tier 2, and more frequent monitoring of nonresponders to intervention. Johnson et al. (2006) likewise suggested monitoring in Tier 1 for 5 weeks, and Tier 2 and Tier 3 monitoring at least two times per week. Vaughn's (2005) frequency spectrum ranges from three times per year for students making adequate progress to weekly for students with persistent reading deficits.

Consistent with their emphasis on efficiency and empiricism, Chun and Witl's (2008) monitoring frequencies depend on measured skills and standard protocol for the assessment (e.g., weekly oral reading fluency and math probes; after 4 or 5 weeks of instruction for reading comprehension probes). Shinn (2008) recommended monitoring weekly rates of improvement among secondary students in Tiers 1 and 2, with nonresponsiveness determined after 4 to 6 weeks, and in Tier 3 , monitoring with greater frequency depending on the intervention. Sugai and Horner (2007a) recommended weekly, monthly, quarterly, and annual collection of student, classroom, and school-wide data to provide balanced information for placement and intervention decisions.

The models differ not only in frequency of administration but in the assessments they employ. Batsche et al. (2008) used CBM and behavioral measures compared to a baseline of peer performance rather than standardized references points. The other six models use standardized CBM tools. However, the combined approach models collect other data 
such as course grades, rates of improvement toward a specified goal, discipline referrals, attendance, suspension, and behavior incident reports.

\section{Decision-making criteria}

Perhaps the greatest variability among models is criteria for introducing an intervention or moving students among tiers. Table 4 describes criteria for five decision points: (a) introduction of a class-wide intervention in Tier 1, (b) moving individual students from Tier 1 to Tier 2, (c) moving individual students from Tier 1 to Tier 3, (d) moving individual students from Tier 2 to Tier 3 , and (e) moving individual students toward Tier 1 .

Screening data may indicate the need for a school- or class-wide intervention in Tier 1. Batsche et al. (2008) suggested such intervention is needed when less than $80 \%$ of students do not score above predetermined benchmarks. Chun and Witl (2008) also compared whole class performance (i.e., median score) to an external standard (i.e., instructional level; Deno \& Mirken, 1977) to determine whether a classwide intervention is needed. Shinn (2008) had a more local or class-specific focus and considered a class-wide intervention necessary when $80 \%$ to $90 \%$ of student needs are not met by the general instruction. Sugai and Horner (2007a) proposed that all students participate in a core social behavior curriculum if school-wide data indicate more than $20 \%$ to $30 \%$ of students are demonstrating behavior problems.

Moving students from Tier 1 to Tier 2 is generally a function of screening data, but in many cases additional data is considered. Batsche et al. (2008) indicated that for each student who scores 2 years below state or district benchmarks, a norm-based gap analysis of individual and class performance determines whether the deficit is specific to the student; if the deficit is student specific, the student moves to Tier 2. Chun and Witt (2008) attempted to discern whether students scoring in the bottom $16 \%$ of the screening assessment lacked motivation or skill by administering a second assessment with a motivational reward. Students who improved their score by $20 \%$ or more remain in Tier 1 where they receive a motivation-focused intervention. Students who improved less than $20 \%$ are placed in Tier 2 and provided an appropriate standard protocol intervention.

Fuchs and Fuchs (2005) and Johnson et al. (2006) both called for collecting additional progress monitoring data in Tier 1 before moving students to Tier 2. Fuchs and Fuchs recommended monitoring students who were either predicted as at risk based on norm-referenced cut points or scored below the $16 \mathrm{~h}$ percentile. A CBM slope discrepancy analysis determines which of these students are placed in Tier 2. The slope discrepancy refers to the difference between the rate of progress evidenced by a student compared to an aim line (i.e., rate of progress) based on local or national norms or a slope greater than the standard error estimate. Johnson et al. linked screening data to such criterion-referenced scores as state assessments to identify students to progress monitor in Tier 1 and a school-determined cut point for movement to Tier 2 . The intent is to improve precision of decision making with additional objective, relevant student data.

Vaughn (2005) recommended placing sludents in Tier 2 when they score below norm-referenced cut scores provided by the assessment tool(s) in one or more critical areas of reading. Shinn (2008) suggested moving students to Tier 2 when CBM grade level proficiency is lower than $75 \%$ of their peers. Sugai and Horner (2007a) suggested moving a student to Tier 2, a classroom-level intervention, based on the number of major behavioral rule violations under the existing practices.

Most of these models are sequential, that is, students participate in Tier 1 and then Tier 2 instruction before moving to Tier 3. However, Batsche et al. (2008) allowed for Tier 1 to Tier 3 movement in casses of clear evidence of a preexisting condition or history of SLD. Likewise, Shinn (2008) moved students who scored below the 10th percentile on the screening assessments directly to Tier 3 or special educaltion, when appropriate. Sugai and Horner (2007a) also allowed for a student to move directly to Tier 3 through the use of a functional behavior assessment (FBA) process.

Slope discrepancy or gap analysis of progress monitoring data drives decisions to move students to Tier 3 in most models. For Batsche et al. (2008), student rates of progress are compared to peers. When the performance gap between a Tier 2 student and his or her peers narrows, the student remains in Tier 2; when the gap is still widening, but at a slower rate, the student receives a different Tier 2 intervention; and when the gap further widens with no change in rate, the student is moved to Tier 3 . Other models prescribe the number of weeks of intervention or data points that must be collected for a slope discrepancy analysis compared to a goal line. For Fuchs and Fuchs (2005) and Johnson et al. (2006), four data points collected during a few weeks of intervention are needed for a movement decision; if the data are consistently above or below the goal line, a change in intervention intensity or method is recommended, with the possibility of beginning a full SLD evaluation and movement to Tier 3 after about 8 weeks. For Vaughn (2005) and Chun and Witt (2008), between 10 and 20 weeks of Tier 2 intervention are needed to determine inadequate progress toward a benchmark, that is, a slope discrepancy, at which time students would be moved to Tier 3. As previously indicated, Shinn (2008) simply used the below 10th percentile on local normreferenced assessments for determining student placement in Tier 3. For Sugai and Horner (2007a) the characteristics of individual students and specific circumstances related to 


\section{TABLE 4. Decision Making Criteria}

\begin{tabular}{|c|c|c|c|c|c|}
\hline $\begin{array}{l}\text { Principle } \\
\text { Author }\end{array}$ & $\begin{array}{l}\text { Need for } \\
\text { Class-wide } \\
\text { Intervention } \\
\text { in Tier } 1\end{array}$ & $\begin{array}{l}\text { Tier } 1 \text { to Tier } 2 \\
\text { Movement }\end{array}$ & $\begin{array}{l}\text { Tier } 1 \text { to Tier } 3 \\
\text { Movement }\end{array}$ & $\begin{array}{l}\text { Tier } 2 \text { to Tier } 3 \\
\text { Movement }\end{array}$ & $\begin{array}{l}\text { Movement } \\
\text { toward Tier } 1\end{array}$ \\
\hline Batsche et al. & $\begin{array}{l}80 \% \text { of the } \\
\text { students are not } \\
\text { scoring above } \\
\text { the benchmark }\end{array}$ & $\begin{array}{l}\text { Students scoring } \\
2 \text { years below state or } \\
\text { district benchmark } \\
\text { predicted as at risk } \\
\text { Example benchmarks: } \\
\text { Academic engage- } \\
\text { ment } 75 \% \text {, high- } \\
\text { stakes test } 70-80 \% \\
\text { accuracy } \\
\text { Norm-based gap } \\
\text { analysis of individual } \\
\text { and class determines } \\
\text { whether the deficit is } \\
\text { specific to that student }\end{array}$ & $\begin{array}{l}\text { Students sequen- } \\
\text { tially progress } \\
\text { through tiers except } \\
\text { in cases of clear } \\
\text { evidence (e.g., pre- } \\
\text { existing condition, } \\
\text { history of SLD) }\end{array}$ & $\begin{array}{l}\text { Student rate of } \\
\text { progress compared } \\
\text { to peer rates; when } \\
\text { performance gap is } \\
\text { narrowing remain } \\
\text { in Tier } 2 \text {; rate of } \\
\text { gap widening slows } \\
\text { but continues to } \\
\text { widen, change inter- } \\
\text { vention; gap con- } \\
\text { tinues to widen } \\
\text { with no change in } \\
\text { rate, move to Tier } 3\end{array}$ & $\begin{array}{l}\text { Students respond- } \\
\text { ing to intervention } \\
\text { and achieving } \\
\text { benchmarks } \\
\text { reverse placement } \\
\text { sequence with } \\
\text { progress } \\
\text { monitoring }\end{array}$ \\
\hline Fuchs \& Fuchs & - & $\begin{array}{l}\text { Students predicted at } \\
\text { risk based on norm- } \\
\text { referenced cut points } \\
\text { or below the 16th } \\
\text { percentile progress } \\
\text { monitored for } 6 \text { to } 8 \\
\text { weeks in Tier } 1 \\
\text { Students scoring } \\
\text { below CBM cut points } \\
\text { (local or national norms } \\
\text { or slope greater than } \\
\text { the standard error } \\
\text { estimate) placed in } \\
\text { Tier } 2\end{array}$ & $\begin{array}{l}\text { Students sequen- } \\
\text { tially progress } \\
\text { through tiers }\end{array}$ & $\begin{array}{l}\text { A minimum of } 3 \\
\text { weeks of interven- } \\
\text { tion and four data } \\
\text { points consistently } \\
\text { above or below the } \\
\text { student goal line } \\
\text { indicates change in } \\
\text { intervention inten- } \\
\text { sity or method }\end{array}$ & $\begin{array}{l}\text { Students per- } \\
\text { forming at class } \\
\text { level return to } \\
\text { Tier } 1 \text { or Tier } 2 \\
\text { instruction from a } \\
\text { higher tier with } \\
\text { progress } \\
\text { monitoring }\end{array}$ \\
\hline Johnson et al. & - & $\begin{array}{l}\text { Students predicted at } \\
\text { risk in criterion refer- } \\
\text { enced screening are } \\
\text { progress monitored } 5 \\
\text { weeks in Tier } 1 \\
\text { From this group, } \\
\text { students performing } \\
\text { below a school- } \\
\text { determined cut point } \\
\text { or demonstrating in- } \\
\text { adequate progress } \\
\text { while scoring in the } \\
\text { "at risk" range placed } \\
\text { in Tier } 2\end{array}$ & $\begin{array}{l}\text { Students sequen- } \\
\text { tially progress } \\
\text { through tiers }\end{array}$ & $\begin{array}{l}\text { Preset rules (e.g., } \\
\text { four consecutive } \\
\text { data points below } \\
\text { the goal line) } \\
\text { prompt an interven- } \\
\text { tion change within } \\
\text { Tier } 2 \\
\text { Comprehensive } \\
\text { evaluation deter- } \\
\text { mines SLD and } \\
\text { Tier } 3 \text { placement }\end{array}$ & $\begin{array}{l}\text { Progress in rate of } \\
\text { improvement or } \\
\text { level in Tier } 2 \text { and } \\
\text { Tier } 3 \text { leads to } \\
\text { reintegration into } \\
\text { a lower tier } \\
\text { placement }\end{array}$ \\
\hline
\end{tabular}


TABLE 4. (continued)

\begin{tabular}{|c|c|c|c|c|c|}
\hline $\begin{array}{l}\text { Principle } \\
\text { Author }\end{array}$ & $\begin{array}{l}\text { Need for } \\
\text { Class-wide } \\
\text { Intervention } \\
\text { in Tier } t\end{array}$ & $\begin{array}{l}\text { Tier } 1 \text { to Tier } 2 \\
\text { Movement }\end{array}$ & $\begin{array}{l}\text { Tier } 1 \text { to Tier } 3 \\
\text { Movement }\end{array}$ & $\begin{array}{l}\text { Tier } 2 \text { to Tier } 3 \\
\text { Movement }\end{array}$ & $\begin{array}{l}\text { Movement } \\
\text { toward Tier } 1\end{array}$ \\
\hline Vaughn & - & $\begin{array}{l}\text { Students scoring be- } \\
\text { low benchmark in one } \\
\text { or more critical areas } \\
\text { of reading using pre- } \\
\text { determined cut scores } \\
\text { established by the } \\
\text { assessment tool(s), } \\
\text { normed on comparable } \\
\text { population, placed in } \\
\text { Tier } 2\end{array}$ & $\begin{array}{l}\text { Students sequen- } \\
\text { tially progress } \\
\text { through tiers }\end{array}$ & $\begin{array}{l}\text { After } 10-20 \text { weeks, } \\
\text { students progress- } \\
\text { ing at an inade- } \\
\text { quate rate to meet } \\
\text { year-end benchmark } \\
\text { may repeat } 10-20 \\
\text { weeks of Tier } 2 \\
\text { intervention } \\
\text { Students making } \\
\text { no or very limited } \\
\text { progress may be } \\
\text { placed in Tier } 3\end{array}$ & $\begin{array}{l}\text { Students placed in } \\
\text { Tier } 1 \text { when making } \\
\text { adequate progress } \\
\text { toward year-end } \\
\text { benchmark and } \\
\text { attaining instruc- } \\
\text { tional goals }\end{array}$ \\
\hline Chun \& Witt & $\begin{array}{l}\text { CBM probe data } \\
\text { indicate the } \\
\text { median student } \\
\text { score is below } \\
\text { instructional level }\end{array}$ & $\begin{array}{l}\text { Students scoring in } \\
\text { bottom } 16 \% \text { of instruc- } \\
\text { tional level on CMBs } \\
\text { performance/skill } \\
\text { assessment } \\
\text { Students improving } \\
>20 \% \text { on perfor- } \\
\text { mance/skill assess- } \\
\text { ment and scoring in } \\
\text { instructional range } \\
\text { provided a motivation } \\
\text { intervention in Tier } 1 \\
\\
\text { Students improving } \\
<20 \% \text { placed in Tier } 2 \\
\text { and matched by pre- } \\
\text { determined criteria } \\
\text { with standard protocol } \\
\text { interventions }\end{array}$ & $\begin{array}{l}\text { Students sequen- } \\
\text { tially progress } \\
\text { through tiers }\end{array}$ & $\begin{array}{l}\text { Students placed in } \\
\text { Tier } 3 \text { when insuffi- } \\
\text { cient progress in } \\
\text { Tier } 2 \text { is evidenced } \\
\text { by an increasing } \\
\text { slope discrepancy } \\
\text { between progress } \\
\text { data and a predeter- } \\
\text { mined aim after } \\
10-15 \text { intervention } \\
\text { sessions }\end{array}$ & $\begin{array}{l}\text { Students are } \\
\text { moved to lower } \\
\text { tier based slope } \\
\text { discrepancy } \\
\text { improvements and } \\
\text { performance level } \\
\text { similar to the lower } \\
\text { tier }\end{array}$ \\
\hline Sugai \& Horner & $\begin{array}{l}\text { School-wide data } \\
\text { indicate more than } \\
20 \% \text { to } 30 \% \text { of } \\
\text { students demon- } \\
\text { strating behavior } \\
\text { problems }\end{array}$ & $\begin{array}{l}\text { Students who have 0- } \\
1,2-5 \text {, and } 6 \text { or more } \\
\text { major rule violations } \\
\text { to determine who are } \\
\text { responsive to existing } \\
\text { practices and systems } \\
\text { Decision making rules } \\
\text { are made by a con- } \\
\text { sensus of the staff after } \\
\text { examining school-wide } \\
\text { data }\end{array}$ & $\begin{array}{l}\text { Decisions based } \\
\text { on weekly criteria } \\
\text { specified in targeted } \\
\text { interventions (e.g., } \\
\text { Check in/Check } \\
\text { Out, Behavior } \\
\text { Education Pro- } \\
\text { gram, Check and } \\
\text { Connect) }\end{array}$ & $\begin{array}{l}\text { Characteristics of } \\
\text { individual students } \\
\text { and specific cir- } \\
\text { cumstances related } \\
\text { to them (e.g., dif- } \\
\text { ferences in the } \\
\text { severity of behavior, } \\
\text { complexity of envi- } \\
\text { ronment) gathered } \\
\text { through the func- } \\
\text { tional behavior } \\
\text { assessment }\end{array}$ & - \\
\hline
\end{tabular}


them (e.g., differences in the severity of behavior, complexity of environment) gathered through the FBA is the basis for movement to Tier 3 .

When students are responsive to interventions and make adequate progress toward goals, they may move down the tier hierarchy to less intensive services. For each model these reverse assignments are sequential, that is, Tier 3 , to Tier 2, to Tier 1 reintegration.

\section{Specific Learning Disabilities Determination}

With the exception of Sugai and Horner's model, which is not used to determine SLD, the models comply with the IDEA requirements for comprehensive assessment and exclusion of other causes of underachievement, using data collected through RTI processes to support the determination. The differences, however, are at what point in the process a comprehensive evaluation of SLD determination begins. Table 5 illustrates SLD determination methods. Vaughn (2005) viewed SLD determination as taking place within the RTI framework. Likewise, Batsche et al. (2008) would begin the SLD determination process at any time the problem-solving team observes more than a 2-year gap between student performance and grade-level expectations, along with a slow rate of progress during high-quality instruction. In contrast, Fuchs and Fuchs (2005) would begin the determination process when a student is nonresponsive to 8 weeks of Tier 2 instruction. Johnson et al. (2006) described how RTI data can contribute to SLD determination along with a comprehensive evaluation, clinical judgments, and other relevant information. Their guidance is that the intervention must be provided with sufficient dosage to judge student responsiveness. Chun and Witt's (2008) model does not begin the SLD determination process until after the RTI process finds insufficient progress in Tier 3. So too, Shinn (2008) would begin determination after RTI interventions have been exhausted and use the relative achievement discrepancy (RAD) method of comparing a student to local norms.

\section{RESEARCH}

Each model has documented research supporting either component parts or the entire model (Table 6). Overall research of RTI models or components at the elementary level is more robust than at the secondary level. The Batsche et al. (2008) study is supported by 2 years of positive quantitative and qualitative outcome data from a school district in Florida. Fuchs and Fuchs referenced research on designating realistic and ambitious rates of growth using CBM measures in reading, spelling, and math in first and second

\section{TABLE 5. RTI Role in Specific Learning Disabilities Determination}

\section{Principle Author Specific Learning Disability Determination}

Batsche et al.

More than 2 year gap between performance and grade-level benchmark, along with low rate of progress with high quality instruction triggers SLD determination procedure

Comprehensive assessment is needed to investigate other causes of underachievement and exclusion factors as per IDEA

Fuchs \& Fuchs

8 weeks of nonresponsiveness to intervention at tier 2 triggers comprehensive evaluation in compliance with IDEA law

Tier 3 is considered special education

Johnson et al.

RTI data contributes to SLD determination, along with comprehensive evaluation, clinical judgments, and other relevant information from interdisciplinary team in compliance with IDEA law The final tier of RTI is special education

Vaughn

SLD identification takes place within the RTI framework

Shinn

Special education determination follows nonresponsiveness in RTI

Relative Achievement Discrepancy (RAD), comparing a student to local norms, used to determine SLD

Chun \& Witt

SLD determination process occurs after insufficient progress in Tier 3

Problem-solving process with progress monitoring data used to make referral and eligibility decisions Data and documentation collected through STEEP RTI on appropriate instruction, student motivation, fidelity, sustained lack of student response, and educational need is used in SLD determination process 
TABLE 6. Model Research Context and Findings

\begin{tabular}{|c|c|c|}
\hline Principle Author & Context & Findings \\
\hline Batsche et al. & $\begin{array}{l}\text { Elementary } \\
\text { Academic } \\
\text { Behavioral }\end{array}$ & $\begin{array}{l}2 \text { years of pilot site implementation in Florida school yielded positive results in } \\
\text { grades } \mathrm{K}-3 \text {, except for students with most intense instructional needs in } \\
\text { second and third grades, who had negligible results (Batsche et al., 2008) }\end{array}$ \\
\hline Fuchs \& Fuchs & $\begin{array}{l}\text { Elementary } \\
\text { Reading } \\
\text { Spelling } \\
\text { Math }\end{array}$ & $\begin{array}{l}\text { Research focused on the CBM component of RTI, specifically designating } \\
\text { realistic and ambitious rates of growth using CBM measures in reading, } \\
\text { spelling, and math in grades } 1 \text { and } 2 \text { (Fuchs \& Fuchs, 1993) } \\
\text { Issues affecting the development of decision-making rules for selecting } \\
\text { students for Tier } 2 \text { interventions in grade } 1 \text { (Compton et al., 2006) } \\
\text { Efficacy of math tutoring for students in grade } 1 \text { (Fuchs et al., 2005) }\end{array}$ \\
\hline Johnson et al. & $\begin{array}{l}\text { Elementary } \\
\text { Reading }\end{array}$ & $\begin{array}{l}19 \text { schools found to be engaged in one or more of the practices in this model } \\
\text { (Johnson et al., 2006) } \\
\text { Model developed from this study but not validated by it }\end{array}$ \\
\hline Vaughn & $\begin{array}{l}\text { K-3 } \\
\text { Middle school } \\
\text { Reading }\end{array}$ & $\begin{array}{l}\text { RTI as a viable option in identifying second grade students with reading } \\
\text { problems Naughn et al., 2003) } \\
\text { Middle school mixed results; some students demonstrated progress, others } \\
\text { made little or no progress in either intervention or traditional reading class } \\
\text { (Denton et al., 2008) }\end{array}$ \\
\hline Shinn & $\begin{array}{l}\text { Secondary } \\
\text { Reading, Math, \& Writing } \\
\text { in content courses }\end{array}$ & $\begin{array}{l}\text { CBM Reading Maze in high school using eighth grade norms for cutoff } \\
\text { decisions (Shinn, 2008) }\end{array}$ \\
\hline Chun \& Witt & $\begin{array}{l}\text { K-12 } \\
\text { Reading } \\
\text { Math } \\
\text { Writing }\end{array}$ & $\begin{array}{l}\text { Improved student achievement in Tier } 2 \text { and for Tier } 1 \text { in schools with pervasive } \\
\text { issues NanDerHeyden \& Burns, 2005; VanDerHeyden et al., 2007) } \\
\text { Reduced overrepresentation in LD for ethnicity, gender, and achievement level } \\
\text { NanDerHeyden \& Witt, 2005) } \\
\text { Reduced evaluation referrals and associated costs and improved referral } \\
\text { accuracy (VanDerHeyden et al., 2007) } \\
\text { Decision rules and benchmark standards validated for categorizing problems at } \\
\text { Tier } 1 \text { and } 2 \text { (VanDerHeyden, Witt, \& Naquin, 2003; VanDerHeyden et al., 2007) } \\
\text { Validation of one rather than three screening probes and benchmarks used for } \\
\text { tier categorization (Ardoin et al., 2004) }\end{array}$ \\
\hline Sugai \& Horner & $\begin{array}{l}\text { Middle school transition } \\
\text { Behavior }\end{array}$ & $\begin{array}{l}\text { Behavioral interventions at all three tiers supported by research } \\
\text { (Sugai \& Horner, 2007a) } \\
\text { PBS approach supported by randomized control trials (Sugai \& Horner, 2007b) }\end{array}$ \\
\hline
\end{tabular}

grade (Fuchs \& Fuchs, 1993), issues alfecting the development of decision-making rules for selecting students for Tier 2 interventions in first grade (Compton, Fuchs, Fuchs \& Bryant, 2006), and the eflicacy of math tutoring for students in first grade (Fuchs et al., 2005). Nineteen elementary schools engaged in one or more commendable practices in the Johnson et al. proposed model (2006). Chun and Witt (2008) referenced research indicating improved achievement for both at-risk students and general education students in schools with pervasive Tier 1 issues (VanDerHeyden \& Will, 2005; VanDerHeyden, Will, \& Gilbertson, 2007). Sugai and Horner refer to three randomized control trials that support the PBIS approach (Sugai \& Horner, 2007a). Vaughn is supported by a study of second grade students at risk for reading difficulties (Vaughn, Linan-Thompson, \& Hickman, 2003) and a recent study of students at the middle school level where results were mixed (Denton, Wexler, Vaughn, \& Bryan, 2008).

\section{CONCLUSION}

No doubt these models' developers and advocales will pursue additional development and validation work from their respective viewpoints. Likewise, schools will continue 
to refine their practices. An important and seemingly obvious conclusion from this summary is that many of the components associated with RTI have been carefully researched and evaluated. We note, however, that this research has had a narrow, explicit focus with defined research protocols. In contrast, the literature is very limited on fully developed models and their scaling and sustainability across multiple school districts, grade levels, content focus, and implementation supports. Their application to SLD determination has not been tested in a comparison research study of alternative assessment approaches. Currently, as state education agencies and districts pursue an adoption, adaptation, implementation, and scaling up of RTI, they are encouraged to make a careful review of available research and supporting evidence. This description and comparison among the seven models illustrates the many decision points that are inherent to RTI complexities. The irony is that while researchers, policy makers, and advocates are pushing for rigorous, high fidelity implementation of screening, progress monitoring, interventions, and decision rules, this goal for practitioners seems to be a higher standard than has been demonstrated by the supporting research. Researchers and practitioners alike will wait to see how the current broad support of RTI withstands the challenges that coexist with broad implementation across the landscape of the US P-12 educational system.

\section{REFERENCES}

Ardoin, S., Witt, J., Suido, S., Connell, J., Koenig, J., Reseter, J. et al. (2004). Examining the incremental benefits of administering a maze and three versus one curriculum based measurement reading probes when conducting universal screening. School Psychology Review 33(2), 218-234.

Batsche, G. (2006). Response to Intervention: Policy Considerations and Implememation. Alexandria. VA: National Association of State Directors of Special Education, Inc.

Batsche, G., Curtis, J., Dorman, C., Castillo, J., \& Porter, L. J. (2008). The Florida problem solving/response to intervention model: Implementing a statewide initiative. In S. Jimerson, M. Burns. \& A. VanDerHeyden (Eds.) Handbook of response wo imtervention: The science and practice of assessmem and intervention (pp. 378-395). New York. NY: Springer.

Bocala, C.. Mello, D., Reedy, K., \& Lacireno-Raquet, N. (2009). Features of state response to intervention iniriatives in Northeast and Islands Region states (Issues \& Answers Report, REL 2009-No. 083). Washington. DC: US Department of Education, Institute for Education Sciences, National Center for Education Evaluation and Regional Assistance. Regional Education Laboratory Northeast and Islands.

Compton, D., Fuchs, D., Fuchs, L. S., \& Bryant, J. (2006). Selecting at-risk readers in first grade for early intervention: A two-year longitudinal study of decision rules and procedures. Journal of Educational Psychology, 98(2). 394-409.
Council for Exceptional Children (CEC). (2008). CEC's position on response to intervention (RTI). Teaching Exceptional Children, 40(3), 74-75.

Chun, M., \& Witt, J. (2008). System to enhance educational performance. Retrieved from http://www.isteep.com/index.html

Deno, S., \& Mirkin, P. (1977). Data-based program modification: A manual. Reston, VA: Council for Exceptional Children.

Denton, C., Wexler, J., Vaughn, S.. \& Bryan. D. (2008). Intervention provided 10 linguistically diverse middle school students with severe reading difficulties. Learning Disabilities Research \& Practice, 23(2), 79-89.

Fletcher, J., \& Vaughn, S. (2009). Response to intervention models as alternatives to traditional views of learning disabilities: Responsc to commentaries. Society for Research in Child Development, $3(1), 48-50$.

Fuchs, D.. \& Deshler, D. (2007). What we need to know about responsiveness to intervention (and shouldn't be afraid to ask). Leaming Disabilities Research \& Practice, 22(2), 129-136.

Fuchs, D., \& Fuchs, L. S. (2005). Responsiveness-to-intervention: A blueprint for practitioners, policymakers. and parents. Teaching Exceptional Children, 38(1), 57-61.

Fuchs, D., Fuchs, L., \& Compton, D. (2004). Identifying reading disabilities by responsiveness-to-instruction: Specifying measures and criteria. Learning Disabilities Quarterly, 27(4), 216-227.

Fuchs, L., Compton, D., Fuchs, D., Paulsen, K., Bryant, J., \& Hamletl, C. (2005). The prevention, identification, and cognitive deterninants of math difficulty. Journal of Educational Psychology: 97(3), 493-513.

Fuchs, L., \& Fuchs, D. (1992). Identifying a measure for monitoring student reading progress. School Psychology Review. $2 /(1), 45-58$.

Fuchs. L.. \& Fuchs. D. (1993). Formative evaluation of academic progress: How much growth can we expect? School Psychology Review: 22(1), 27-48.

Fuchs, L., \& Fuchs, D. (2009). On the importance of a unified model of responsiveness to intervention. Society for Research in Child Development, 3(1), 41-43.

Good, R., \& Kaminski, R. (2002). Dynamic Indicators of Basic Early Literacy Skills (6th ed.). Eugene. OR: Institute for the Development of Educational Achievement. Retrieved from http://dibels. uoregon.edu/measures/orf.php

Griffith, A., Parsons, L., Burns, M., VanDerHeyden, A., \& Tilly, W. D. (2007). Response to Intervention: Research for practice. Alexandria. VA: National Association of State Directors of Special Education. Inc.

Hasbrouck, J., \& Tindal, G. (1992). Curriculum-based oral reading fluency norms for students in grades 2 through 5. Teaching Exceptional Children, 24(3), 41-44.

Hollenbeck, A. (2007). From IDEA to implementation: A discussion of foundational and fulure responsiveness-10-intervention research. Learning Disabilities Research and Practice 22(2). 137-146.

Johnson, E., Mellard, D., Fuchs, D.. \& McKnight, M. (2006). Respomsiveness to imervention (RTl): How: to do it. Lilwrence. KS: National Research Center on Learning Disabilitics.

Johnson, E., Smith, L.. \& Harris, M. (2009). How RTI Works in Sec;ondary Schools. Thousand Oaks. CA: Corwin Press.

Learning Disabilities Association of America (LDA). (2006, Seplember) The role of parents/family in responsiveness to interventom. Author: Pittsburgh, PA.

Mellard, D., Byrd. S., Johnson, E., Tolleison. J.. \& Boesche, L. (2004). Foundations and research on identifying model responsiveness-tointervention sites. Learning Disabilities Quarterly, 27(4). 243-256. 
Mèllard, D., \& Johnson, E. (2008). RTI: A practitioner's guide to implementing response to intervention. Thousand Oaks, CA: Corwin Press.

Mellard, D., McKnight, M., \& Jordan, J. (2010). RTI tier structures and instructional intensity. Manuscript submitted for publication.

Mellard, D., McKnight, M., \& Woods, K. (2009). Response to intervention screening and progress monitoring practices in 41 local schools. Learning Disabilities Research and Practice, 24(4), 186-195.

Mellard, D., McKnight, M., Woods, K., \& Frey, B. (n.d.). School-wide student outcomes as evidential validity of response to intervention frameworks. Manuscript submitted for publication.

Reynolds, C., \& Shaywitz, S. (2009). Response to intervention: Prevention and remediation, perhaps. Diagnosis, no. Society for Research in Child Development, 3(1), 44-47.

Shinn, M. R. (2008). Implementation in secondary schools. In S. Fernley, S. D. LaRue, \& J. Norlin, (Eds.). What do I do when: Answer book on RTI. (pp. 8:1-17). Arlington, VA: LRP Publications.

Sugai, G., \& Horner, R. (2007a). Response to intervention logic and positive behavior support [PowerPoint slides]. Retrieved from http://www.pbis.org/main.htm

Sugai. G., \& Horner, R. (2007b). Evidence base for school-wide positive behavior support [PDF file]. Retrieved from http://www.pbis. org/main.htm
VanDerHeyden, A. M., \& Burns, M. K. (2005). Using curriculumbased assessment and curriculum-based measurement 10 guide elementary mathematics instruction: Effect on individual and group accountability scores. Assessmem for Effective Imtervention. $30,15-31$.

VanDerHeyden, A., \& Witt. J. (2005). Quantifying context in assessment: Capturing the effect of base rates on teacher referral and a problem-solving model of identification. School Psychology Review, 34(2), 161-183.

VanDerHeyden, A., Witl, J., \& Gilbertson, G. (2007). A multi-year evaluation of the effects of a response to intervention (RTI) model on identification of children for special education. Journal of School Psychology, 45(2), 225-256.

VanDerHeyden, A., Witt, J., \& Naquin, G. (2003). The development and validation of a process for screening and referrals to special education. School Psychology Review, 32(2), 204-227.

Vaughn, S. (2005). Interpretation of the 3-tier framework. Retrieved from http://www.texasreading.org/utcrla/materials/3tier_letter.asp

Vaughn, S., Linan-Thompson, S., \& Hickman, P. (2003). Response to instruction as a means of identifying students with reading/learning disabilities. Exceptional Children, 69(4), 391-409. 